Published in final edited form as:

Med Clin North Am. 2020 January ; 104(1): 1-14. doi:10.1016/j.mcna.2019.08.005.

\title{
Approach to the patient with eosinophilia
}

\author{
Fei Li Kuang, MD-PhD \\ Human Eosinophil Section, Laboratory of Parasitic Diseases, National Institute of Allergy and \\ Infectious Disease, National Institutes of Health, Bethesda, Maryland
}

\section{Keywords}

Eosinophil; IL-5; corticosteroids; biologics; hypereosinophilia; eosinophil granule proteins

\section{Introduction}

Physicians may encounter blood or tissue eosinophilia through a routine $\mathrm{CBC}$ with differential or a tissue pathology report. In this article, the basic biology of eosinophils will be reviewed and definitions of blood eosinophilia as well as the challenges of defining tissue eosinophilia will be discussed. Conditions associated with eosinophilia will be briefly discussed as well as a general approach to evaluating eosinophilia. Future challenges include determining which eosinophil-associated diseases benefit from eosinophil-targeted therapy and identifying biomarkers for disease activity and diagnosis.

\section{Eosinophil Biology}

Eosinophils are myeloid cells that were first named by Paul Ehrlich in 1879 due to their bright red staining eosin-fast granules. These cells arise from the bone marrow and are released in mature form, circulate in the periphery and become tissue-resident cells. Eosinophil development depends on several cytokines including IL-5, IL-3 and GM-CSF. IL-5 is also critical for eosinophil activation and survival. Though eosinophils are found in the circulation, they are thought to be primarily tissue dwelling cells, where they are hundred-fold more abundant. In the blood, eosinophils have a half-life of 8 to 18 hours after departing the bone marrow. It is unclear how long they live in various tissues at homeostasis and it is possible their survival could be extended/sustained by exogenous factors such as IL-5.

CORRESPONDING AUTHOR, Fei Li Kuang, 4 Memorial Drive, B1-27, Bethesda, MD 20892, feili.kuang@ nih.gov. DISCLOSURE STATEMENT

The Author has nothing to disclose.

Publisher's Disclaimer: This is a PDF file of an unedited manuscript that has been accepted for publication. As a service to our customers we are providing this early version of the manuscript. The manuscript will undergo copyediting, typesetting, and review of the resulting proof before it is published in its final citable form. Please note that during the production process errors may be discovered which could affect the content, and all legal disclaimers that apply to the journal pertain. 


\section{Eosinophil Granules}

Electron micrographs reveal that eosinophils contain multiple types of granules: primary granules, secondary (eosinophil-specific) granules, small granules and microgranules (secretory vesicles). Primary granules are round and uniformly -dense, and are comprised of Charcot-Leyden crystal protein (CLC, galectin-10), which form the well-known CharcotLeyden crystals associated with the sputum of patients with asthma, described years before the discovery of eosinophils(1). Despite this well-known association, today it is appreciated that these crystals are not pathgnomic for asthma but can form anywhere in which there is an excess of eosinophil turnover.

Eosinophil specific or secondary granules have an electron-dense core and are surrounded by an electron-lucent matrix. These granules are composed of four granule proteins: major basic protein (MBP) which forms part of the core, and three others: eosinophil peroxidase (EPO or EPX), eosinophil-derived neurotoxin (EDN) and eosinophil cationic protein (ECP). A number of preformed chemokines, growth factors and cytokines are also found within eosinophil specific granules such as IL-4, IL-2, GM-CSF, IL-5, IL-13, RANTES, eotaxin and others(2). Small granules contain acid phosphatase and arylsulfatase. Finally, secretory vesicles, also known as microgranules, are dumbbell-shaped and contain various receptors, adhesion molecules and albumin.

Eosinophils also contain lipid bodies which differ from granules since they are enclosed by a phospholipid monolayer. Lipid bodies are the sites of leukotriene synthesis and their formation are induced in a variety of experimental inflammatory conditions as well as in response to various stimuli(3).

Eosinophils utilize a variety of degranulation processes to selectively or completely release their cellular contents. These include classical exocytosis (individual granules fuse with plasma the membrane and discharge its cargo), compound exocytosis (several granules fuse together and then fuse with the plasma membrane), piecemeal degranulation (small components of granules bleb off and fuse with the plasma membrane), and eosinophil cytolysis (4). How these processes are regulated are still being understood. Finally, eosinophils also release DNA nets or traps with intact free granules and this is a regulated pathway of extracellular trap cell death mediated by eosinophils, known as ETosis. Recently, ETosis was directly associated with formation of Charcot Leyden Crystals(5).

\section{Role of Eosinophils}

Eosinophils are thought to be effector cells in the body's defense against parasitic infections and the mechanism of action may differ depending on the parasite. One proposed mechanism of action is by the release of toxic eosinophil granule proteins via ETosis. Other mechanisms include antibody-dependent cytotoxic cell death carried out by both eosinophils and neutrophils in the case of Schistosomiasis(6,7). Eosinophils might use similar mechanisms to cause tissue damage and inflammation in eosinophil-associated diseases.

However, eosinophil-deficient mice can clear some parasitic infections, suggesting at least redundancy in the body's anti-parasite defenses (8). More recently, eosinophils have been ascribed roles in maintaining bone marrow plasma cells, vaccine recall responses, 
modulating a variety of $\mathrm{T}$ cell mediated responses, as well as roles in tissue repair, glucose and fat metabolism, and perhaps tumor surveillance (reviewed in (9)). Many of these studies have been in animal models and the extension to humans has yet to be made. Murine studies also suggest that eosinophils can be divided into inflammatory or homeostatic subsets and it is unclear if these exist in humans.

Of relevance to this chapter is the role that eosinophils play in the pathogenesis of allergic disease. They are physically present in the airways of patients with eosinophilic asthma, within the polyps of those with chronic rhinosinusitis with polyps, and in the gastrointestinal tract of those with eosinophilic GI disease. They can also be present in the skin of those with drug-related skin eruptions.

\section{Definitions of eosinophilia}

\section{Blood Eosinophilia}

In general, the degree of eosinophilia is defined using the absolute eosinophil count, which refers to the number of circulating eosinophils in peripheral blood. This can be ascertained by multiplying the total white blood cell count (WBC) by the percentage of eosinophils. The normal range of blood eosinophils is 0 to 500 cells $/ \mathrm{mm}^{3}$ and the typical percentage is less than 5\% of WBC. However, the presence of eosinophilia cannot be determined by percentage alone since leukopenia would lead to a relative increase in eosinophil percentage, and vice versa.

Humans exhibit diurnal variation in a number of hematologic parameters including blood eosinophil counts, with a recent study showing a median within subject variability of 40 cells $/ \mathrm{mm}^{3}$ or $20 \%$, with the peak occurring at $1 \mathrm{am}$ and the maximum at noon in those with normal range eosinophil counts $(10,11)$. The within-subject change of eosinophil counts in 24 hours in those with elevated eosinophil counts is unknown.

Eosinophilia is defined as greater than 500 eosinophils $/ \mathrm{mm}^{3}$. The degree of eosinophilia can be categorized as mild ( $500-1500$ cells $\left./ \mathrm{mm}^{3}\right)$, moderate $\left(1500\right.$ to 5000 cells $/ \mathrm{mm}^{3}$ ), or severe $\left(>5000\right.$ cells $\left./ \mathrm{mm}^{3}\right)$. Hypereosinophilia is defined as moderate to severe eosinophilia $\geq 1500$ cells $/ \mathrm{mm}^{3}$. To meet the definition for hypereosinophilic syndromes requires evidence of endorgan damage as a result of hypereosinophilia.

The degree of blood eosinophilia is commonly thought to be correlated with the severity or seriousness of disease, but there isn't evidence to support this except anecdotal experience in those with severe eosinophilia and hypereosinophilic syndrome. End organ damage can occur at relatively moderate levels of eosinophilia. A recent study describes a rare group of people with asymptomatic hypereosinophilia and no evidence of end organ damage despite exhaustive and regular evaluation for it (12).

Concomitant medications (such as corticosteroids) and transient medical conditions (bacterial infection) can also mask a greater degree of eosinophilia by temporarily suppressing the absolute eosinophil count. Thus, clinical evaluation and context are important. 


\section{Tissue Eosinophilia}

During homeostatic conditions, most eosinophils reside in tissue with the majority in the gastrointestinal tract except for the esophagus. They are also are also found in the thymus, mammary glands and uterus. Tissue residence is regulated by tissue expression of eosinophil recruiting chemokines, such as eotaxin-1. In pathologic conditions, eosinophils are recruited to other anatomic sites including the lung, skin, and esophagus and they can be further increased in sites that normally contain eosinophils such as the stomach. However, thresholds for what is considered a pathologic increase are not well defined.

The experience with esophageal eosinophilia illustrates how that could change. For the purposes of research and clinical care, a consensus standard was established by a multidisciplinary group of physicians interested in eosinophilic esophagitis in $2007(13,14)$. With the appropriate clinical context and symptoms, and a lack of response to a trial of high-dose proton-pump inhibitors (to treat gastric reflux disease), esophageal tissue demonstrating a peak eosinophil count $\geq 15$ eosinophils per high power field (eos/hpf) was agreed upon to be the minimum standard for diagnosis of eosinophilic esophagitis. This was often accompanied by other histologic features such as basal zone hyperplasia, degranulated appearance of eosinophils, and presence of eosinophilic micro abscesses.

Later studies revealed an entity described as proton-pump inhibitor responsive esophageal eosinophilia (PPI-REE) and transcriptomic studies suggest that this entity is more like eosinophilic esophagitis than gastric reflux disease(15). Thus, the most recent guidelines suggest that a trial of high dose PPI is not required to establish a diagnosis of EoE if the right clinical context is present(16). PPI might be considered as an initial treatment for EoE though whether patients with PPI-REE would retain responsiveness to this treatment remains to be determined.

Beyond the esophagus, eosinophils are normally found in the GI tract and thus may play a role in maintaining homeostasis. There are few studies describing normal GI tissue eosinophil levels $(17,18)$. Debrosse and colleagues performed a study in a pediatric population undergoing endoscopy with biopsies that were ultimately found to be normal. They proposed using two times the peak eosinophil counts in each GI segment as the threshold for tissue eosinophilia. This results in different segments of the large bowel having different cut-offs, with the ascending colon having the highest threshold for diagnosis. Currently, stomach eosinophilia is defined as having $30 \mathrm{eos} / \mathrm{hpf}$ in at least five high power fields for the purposes of clinical and natural history study enrollment, with a similar threshold for the small bowel. More studies are needed to determine if eosinophil number alone, to what threshold, defines disease in each segment of the GI tract(19).

\section{Interpreting Eosinophilia}

As with any laboratory value, clinical context is important. Is the abnormal value a new finding and is it persistent? What are the clinical symptoms and concomitant medications associated with the laboratory abnormality, and how does that change over the course of time and/or treatment? Thus, a thorough and detailed history and physical exam are critical in this setting. Mild eosinophilia in a patient taking high dose corticosteroid while febrile 
would be interpreted differently than a patient with no symptoms but found to have a moderate eosinophilia. Finally, as will be seen in the next sections, whether eosinophils themselves are pathogenic and disease-causing versus being part of the cellular milieu that are recruited to the site of disease, remain open questions.

\section{Conditions Associated with Eosinophilia}

Eosinophilia is associated with several medical conditions and disease states, including allergic diseases. This section will touch on general categories and a non-exhaustive list of specific conditions, from common ones, such as a drug reaction, to rare diseases of eosinophilia, such as hypereosinophilic syndromes.

\section{Infections}

Eosinophilia is classically associated with parasitic diseases such as helminth infections. There are reviews devoted to this topic(20) and one approach is to consider the type of patient, previous travel and exposure history to guide evaluation. If a patient is suspected of having a parasitic infection, referral to an infectious disease specialist may be warranted.

HIV infection can be associated with eosinophilia (21), though there are confounding factors such as medication usage or concomitant opportunistic or parasitic infections. In a casecontrol study, approximately $10 \%$ of treatment-naïve HIV patients had associated blood eosinophilia and a slightly higher HIV RNA viral load, without differences in age, sex, race or baseline CD4 counts, as compared to a control group of treatment naïve HIV patients without blood eosinophilia (22). Interestingly, the presence of a rash, including but not exclusive to eosinophilic folliculitis, was more likely in those with blood eosinophilia in that study (46\% in cases vs $25 \%$ in controls). Both tuberculous (23-25) and nontuberculous mycobacterial infections(26) are associated with eosinophilia. It is noteworthy that bacterial infections are associated with eosinopenia.

Treatment is targeted at the underlying infection. Infection resolution is often associated with decrease or resolution of eosinophilia, though this might not occur immediately. For example, after single-dose diethylcarbamazine or ivermectin treatment for Loa loa infection, post-treatment associated eosinophilia can be observed and may take days to weeks to resolve (27). In a study of Strongyloides stercoralis infection in rural India, eosinophilia was decreased six months post-treatment, and in some cases, not necessarily resolved (28). Rarely, hypereosinophilic syndrome can occur as a result of active parasitic infection $(29,30)$, and treatment in those cases are still aimed at the underlying infection.

\section{Medications}

Medications are the most common cause for persistent eosinophilia in the developed world, but the laboratory finding is neither sensitive nor specific for a drug reaction. In a study of inpatient acute cutaneous drug reactions $(\mathrm{n}=55)$, blood eosinophilia (defined as $>700$ cells $/ \mathrm{mm}^{3}$ ) was seen in only $18 \%$ and tissue eosinophils were seen in $24 \%$ of cases (31). Furthermore, only half of those with biopsy-proven tissue eosinophils (i.e. 12\% of cases) had concurrent blood eosinophilia. Thus, lack of eosinophilia in blood or eosinophils detected on tissue biopsy should not be used to rule out allergic or eosinophilic drug 
reaction. Finally, there are many allergic drug reactions that are not thought to be mediated by or associated with eosinophils including classic IgE-mediated type 1 hypersensitivity, delayed hypersensitivity (contact dermatitis), serum sickness and toxic epidermal necrolysis (TEN)/ Stevens Johnson syndrome (SJS).

Drug reactions associated with eosinophilia can range from benign, transient eosinophilia with or without skin eruption, to more severe involvement of internal organs such as in drug reaction with eosinophilia and systemic symptoms (DRESS) (32). In a single-center prospective study to investigate inpatient eosinophilic drug reactions, the incidence of eosinophil associated drug reactions was found to be 16.67 per 10,000 admissions, with 56\% of those being asymptomatic, $13 \%$ with skin and soft tissue reactions, $7 \%$ with visceral involvement and 23\% with clinical presentation consistent with DRESS(33).

DRESS is a potentially life-threatening disease and worth discussing in more detail. It presents in a delayed fashion (weeks) after drug initiation with symptoms that include fever (90-100\%), often high-grade, along with a morbilliform rash. There can also be facial swelling in the early phase. These can be followed or accompanied by visceral involvement with the most common two being hepatic and lymphadenopathy, but can include myocarditis, colitis, pneumonitis and CNS involvement.

Drugs commonly associated with DRESS include allopurinol, sulfasalazine, antibiotics (beta-lactam antibiotics, minocycline, dapsone, sulfamethoxazole, vancomycin), anticonvulsants (lamotrigine, valproic acid, carbamazepine, phenobarbital, phenytoin), antiretroviral agents (abacavir, nevirapine, raltegravir, efavirenz), strontium ranelate and others(32).

The etiology of the disease is thought to be due to a combination of activated CD8+ T cells directed against the drug and viruses. Laboratory findings include eosinophilia, changes in $\mathrm{T}$ helper cytokine milieu and viral reactivation such as that detected with HHV6 PCR. Recent studies are beginning to parse out the factors that are associated with specific drugs or etiologies. Examples include correlation of elevated serum TARC levels in DRESS patients with HHV6 reactivation (34) and clinical/laboratory differences between those with DRESS triggered by lamotrigine versus other drugs(35). While there have been studies that isolate drug-specific T cells from blood and skin of patients with DRESS, there currently is no validated testing to ascertain which drug is culprit.

Diagnosis of DRESS can be difficult due to an incomplete clinical picture or an atypical presentation and thus diagnostic scoring systems were instituted to simplify the approach, an example being the RegiSCAR scoring system whose criteria are listed in Table 1(36,37). Treatment for mild cases of DRESS include drug withdrawal and supportive measures. Skin manifestations can be treated with topical corticosteroids whereas patients with visceral organ involvement, high dose corticosteroids are often used. Complete recovery after drug withdrawal can take weeks to months. Prior retrospective studies describe a mortality rate of 5 to $10 \%$, while a recent prospective study reported 2 deaths out of 117 (1.7\%) during the acute phase(37-39). 
While any medication can result in a drug reaction, there are specific ones that are more well known for causing specific reactions such as delineated above for DRESS, and in some cases this is due to genetic susceptibility. For example, severe cutaneous adverse reactions in response to abacavir, allopurinol, carbamazapine and nevirapine are more likely to occur in people with specific HLA-alleles. HLA-allele testing prior to initiation of carbamazepine and abacavir is now recommended.

It is also important to query the patient on use of supplements and over the counter medications. Eosinophil myalgia syndrome (EMS) was described after exposure to a contaminant in the supplement L-tryptophan in the late 1980s, and resulted in skin thickening, myalgias and other visceral organ involvement (40). Finally, there are also allergic drug reactions that are not associated with eosinophilia nor eosinophil-mediated, such as Stevens-Johnson Syndrome.

\section{Malignancy}

An occult neoplasm may be associated with blood eosinophilia and in those patients with new onset persistent eosinophilia without a clear cause, an age-appropriate evaluation for malignancy should be undertaken. A thorough history and physical exam might reveal symptoms and findings such as fevers, chills, weight loss, lymphadenopathy or splenomegaly, to direct specific evaluation. Laboratory evaluation might reveal alterations in other hematologic parameters (ie. cytopenias, dysplastic appearing cells on smear). In such cases, a hematologic cause for eosinophilia should be pursued by referral to specialists. Various forms of mastocytosis are also associated with significant eosinophilia $(41,42)$ but in those cases, treatment is tailored towards the mastocytosis. Finally, after the malignancy is removed or treated, eosinophilia generally does resolve. In stem cell transplant for treatment of malignancy, post-transplant eosinophilia can be seen sometimes as part of graft versus $\operatorname{host}(43,44)$.

\section{Autoimmune disorders/Immune Dysregulation}

A number of autoimmune disorders are associated with mild to moderate blood eosinophilia. In some cases, eosinophils are also found at the site of disease such as in Eosinophilic Granulomatosis with Polyangiitis (EGPA-formerly known as Churg-Straus). It is unclear if eosinophils are causing direct damage, are attempting to resolve the inflammation, or are innocent bystanders. Generally, treatments of autoimmune disease with or without blood eosinophilia are the same. A recent phase 3 trial of anti-IL5 therapy to treat EGPA suggests that eosinophils themselves play some pathogenic role, since there was a significant decrease in disease flares in treated patients despite tapering of concomitant corticosteroid therapy which would target cells beyond eosinophils (45). Anti-IL5 is now an approved therapy for EGPA. It remains to be seen whether eosinophil-targeted therapy would be helpful in other autoimmune diseases with associated blood eosinophilia.

Primary immunodeficiencies (PID) are associated with eosinophilia, and infrequently these can be more apparent in adulthood with clinical presentation consisting of an array of autoimmune disorders (46). One explanation for the correlation is that oligoclonal/restricted lymphocyte repertoires, such as that seen in a number of PID, lead to eosinophilia and this 
was experimentally demonstrated in a murine model(47). Again, definitive treatment is aimed at the underlying PID.

\section{Atopic Disorders}

Mild to moderate eosinophilia can be associated with a wide variety of atopic disorders including atopic dermatitis, allergic rhinitis and asthma. Eosinophilic GI disease (EGID) such as eosinophilic esophagitis is diagnosed by tissue eosinophilia along with clinical context. In eosinophilic esophagitis, very mild blood eosinophilia is often seen while in eosinophilic gastroenteritis (stomach or small bowel involvement), there is reportedly moderate to severe blood eosinophilia but larger studies are needed to confirm.

Many of these diseases are treated with corticosteroids (topical or systemic) which would target both eosinophils and other immune cells such as lymphocytes that might be the inciting cell population. In the case of EGID, empiric food elimination diets have also been used particularly in the pediatric population and have a 70-80\% efficacy in eosinophilic esophagitis(48-50).

Most recently, treatment with eosinophil-targeted therapies in a subset of eosinophilic asthma patients using anti-IL5 or anti-IL5R results in increased lung function and decrease diseases flares, and now both types of biologics have been approved for use as add-on to maintenance therapies in severe asthma with eosinophilic phenotype (moderate-to-severe for anti-IL5R). This suggests that eosinophils play a direct pathogenic role at least in certain asthma endotypes. On the other hand, treatment with anti-IL4RA (blocking both IL-4 and IL-13 signaling) in all comers with moderate to severe asthma resulted in similar clinical improvement but was accompanied by transient increases in peripheral eosinophil counts as well as serum eosinophil granule proteins (51). With some individual exceptions (see supplemental appendix of reference (51)), the resultant eosinophilia did not appear to cause harm or affect efficacy, though a subgroup analysis stratifying among those with different degrees of peripheral blood eosinophil increase was not presented. function.

\section{Other Conditions}

Hypereosinophilic Syndrome (HES) is a group of rare diseases defined as exhibiting a persistent blood eosinophilia of $\geq 1500$ cells $/ \mathrm{mm}^{3}$ (over at least 4 weeks, unless imminent treatment was necessary (52)) and evidence of end organ damage as a result of this eosinophilia. This definition has evolved over the years since Chusid first described the disease. One way of subdividing this group can be into clinical subtypes (Table 1, reviewed in(53)). In myeloid HES, there is a genetic aberration in the eosinophil and/or myeloid lineage of cells, and this is accompanied by a dysplastic appearance of the eosinophils, elevated serum vitamin B12 and tryptase, and clinical findings that could include splenomegaly. In lymphoid HES there is an aberrant $\mathrm{T}$ cell clonal population (often CD3dimCD4 positive) that secretes high levels of IL-5, thus promoting eosinophilia. Occasionally, patients with single-organ restricted eosinophilic diseases such as EGID can have peripheral blood eosinophilia that meet HES criteria and these patients are categorized as Overlap HES. Associated HES is a category used for HES that develops in the presence of a malignancy or parasitic infection, or a drug reaction. Familial HES consists of rare 
families with autosomal dominant inheritance of blood eosinophilia, and often without many symptoms $(54,55)$.

A small group of patients exhibit hypereosinophilia but do not have discernible symptoms or end organ damage despite deliberate evaluation for them over a number of years(12). These people are deemed to have hypereosinophilia of unknown significance (HE-US), remain untreated but monitored over the years.

\section{Workup for Eosinophilia}

In addition to history and physical exam, it would be useful to obtain a repeat $\mathrm{CBC}$ with differential (to look for persistent eosinophilia), a basic metabolic panel and liver function test, and a peripheral blood smear to examine for dysplastic looking cells. Depending on clinical context (and urgency) and likely etiologies, work-up for eosinophilia will differ and sometimes subspecialist referral is warranted. It would be reasonable for an older patient with lymphadenopathy, fevers, weight loss and cytopenias to be referred to a hematologist/ oncologist. A patient who has eosinophilia in association with a long history of GI symptoms, such as dysphagia, should be evaluated by both a gastroenterologist and an allergist/immunologist with experience in EGIDs. Finally, the young man with new evidence of cardiac dysfunction in the setting of severe eosinophilia, should be urgently evaluated for myeloid HES with bone marrow biopsy and testing for the causative genetic changes including FIP1L1-PDGFRA translocation. Summary guidelines on evaluating for HES can found in (53) and include testing such as serum tryptase, vitamin B12, serum IgE and flow cytometry for aberrant $\mathrm{T}$ cells, as well as imaging, cardiac and pulmonary testing when indicated.

There are no validated tests to ascertain food triggers in EGID besides repeat invasive tissue sampling and thus it would not be helpful to measure for a panel of food specific IgE or IgG4. Measuring serum IL-5 has not been useful thus far in determining etiology of eosinophilia though it is a predictor of response to anti-IL5 therapy in a subset of HES patients(56). Furthermore, limited data indicate that serum IL-5 is affected by medications such as corticosteroids. Eosinophil granule proteins (MPO, EDN, EPO, ECP) can be measured in the blood and other body fluids and tissues, but the exact correlation with both diagnosis and disease activity have yet to be validated.

Finally, isolated, asymptomatic blood eosinophilia can be the earliest sign of HES(57). Prospective multi-center studies are needed to better understand how many of such patients go on to develop hypereosinophilia or HES. Initial workup for hypereosinophilic syndromes is separately described (53) but in brief, should include evaluation for myeloid HES if AEC is markedly elevated $\left(>5000\right.$ cells $/ \mathrm{mm}^{3}$ ) with blood tests (tryptase, Vitamin B12), genetic testing for associated mutations such as FIP1L1/PDGFRA and bone marrow evaluation. Where the clinical scenario remains concerning (male patient with elevated tryptase/B12, presence of splenomegaly and dysplastic appearing eosinophils) despite negative gene testing, it is worthwhile to refer to a HES specialist since false negatives have been reported(58). 
Since symptoms can occur without warning, it is useful to periodically monitor an elevated eosinophil count in the absence of symptoms or evidence of end organ damage, with quarterly or annual history and physical exam, accompanied by targeted testing. There are not published consensus recommendations as to interval testing modalities because patients can have very different types of end organ involvement. It would be reasonable to perform yearly blood work, lung function tests and echocardiography in those with hypereosinophilia, especially in the first five years(12). In those with overlap HES (EGID, EPGA etc), rises in eosinophil counts may precede or accompany a disease flare and those counts often return to the patient's baseline with treatment. If different or new symptoms accompany that disease flare, there should be targeted evaluation of those findings to elucidate whether those are due to a new disease process or eosinophil-related.

\section{Future Directions: Role of eosinophil-targeted therapy}

In the past few years, eosinophil-targeted therapy has been shown to reduce disease flares and achieved FDA-approval in severe eosinophilic asthma (anti-IL5: mepolizumab (100mg SC) and reslizumab (weight based); anti-IL5R: benralizumab) and EGPA (mepolizumab 300mg SC). In cases of life-threatening, treatment-refractory hypereosinophilic syndrome, high dose mepolizumab (300mg up to $700 \mathrm{mg}$ ) can be obtained through application to the compassionate use study (NCT00244686). A small phase 2 study of benralizumab (antiIL5R) therapy for patients with severe hypereosinophilic syndrome demonstrated suppression of peripheral eosinophilia and symptomatic improvement over 48 weeks in 74 $\%$ of patients (59). Larger, phase 3 multi-center trials are still needed for both biologics in HES.

Drugs that target other eosinophil membrane receptors or have eosinophil-lowering effects without a defined mechanism are being evaluated in a variety of eosinophil-associated conditions(60-62).

Whether the IL5/IL5R biologics or other eosinophil-targeting therapies will be useful in other acute or chronic eosinophil-associated diseases remains an open question. For example, would they be useful in DRESS in the acute setting? Could they block posttreatment eosinophilia and reactions during treatment of certain helminth infections? These are unexplored questions.

There is over a decade of safety data in using anti-IL5 therapy for hypereosinophilic syndromes from a compassionate use study $(56,63)$. However, the effects of long-term eosinophil depletion with anti-IL5R (benralizumab) therapy is unknown and may be different as this therapy appears to result in a more complete depletion of eosinophils, including tissue resident ones. Finally, it is worth bearing in mind that eosinophils might not be pathogenic in all conditions with which they are associated(64). Hopefully in the next decade with the use of these new eosinophil-targeted biologics, we will learn in which diseases eosinophil-lowering is beneficial.

\section{Acknowledgements}

This research was supported by the Intramural Research Program of the NIH, NIAID, LPD. 


\section{References}

1. Sakula A Charcot-Leyden crystals and Curschmann spirals in asthmatic sputum. Thorax. 1986 7;41(7):503-7. [PubMed: 3538483]

2. Davoine F, Lacy P. Eosinophil cytokines, chemokines, and growth factors: emerging roles in immunity. Front Immunol. 201411 10;5:570. [PubMed: 25426119]

3. Melo RCN, Weller PF. Unraveling the complexity of lipid body organelles in human eosinophils. J Leukoc Biol. 2014 11;96(5):703-12. [PubMed: 25210147]

4. Spencer LA, Bonjour K, Melo RCN, Weller PF. Eosinophil secretion of granule-derived cytokines. Front Immunol. 201410 27;5:496. [PubMed: 25386174]

5. Ueki S, Tokunaga T, Melo RCN, Saito H, Honda K, Fukuchi M, et al. Charcot-Leyden crystal formation is closely associated with eosinophil extracellular trap cell death. Blood. 201811 15;132(20):2183-7. [PubMed: 30154112]

6. Sher A, Butterworth AE, Colley DG, Cook JA, Freeman GL, Jordan P. Immune responses during human schistosomiasis mansoni. II. Occurrence of eosinophil-dependent cytotoxic antibodies in relation to intensity and duration of infection. Am J Trop Med Hyg. 1977 9;26(5 Pt 1):909-16. [PubMed: 907053]

7. Moser G, Sher A. Studies of the antibody-dependent killing of schistosomula of Schistosoma mansoni employing haptenic target antigens. II. In vitro killing of TNP-schistosomula by human eosinophils and neutrophils. J Immunol. 1981 3;126(3):1025-9. [PubMed: 7462624]

8. Lee JJ, Rosenberg HF, editors. Eosinophils in Health and Disease. Elsevier; 2012.

9. Weller PF, Spencer LA. Functions of tissue-resident eosinophils. Nat Rev Immunol. 2017 12;17(12):746-60. [PubMed: 28891557]

10. Hilderink JM, Klinkenberg LJJ, Aakre KM, de Wit NCJ, Henskens YMC, van der Linden N, et al. Within-day biological variation and hour-to-hour reference change values for hematological parameters. Clin Chem Lab Med. 20176 27;55(7):1013-24. [PubMed: 28002028]

11. Sennels HP, Jørgensen HL, Hansen A-LS, Goetze JP, Fahrenkrug J. Diurnal variation of hematology parameters in healthy young males: the Bispebjerg study of diurnal variations. Scand J Clin Lab Invest. 2011 11;71(7):532-41. [PubMed: 21988588]

12. Chen Y-YK, Khoury P, Ware JM, Holland-Thomas NC, Stoddard JL, Gurprasad S, et al. Marked and persistent eosinophilia in the absence of clinical manifestations. J Allergy Clin Immunol. 2014 4;133(4):1195-202. [PubMed: 23987798]

13. Furuta GT, Liacouras CA, Collins MH, Gupta SK, Justinich C, Putnam PE, et al. Eosinophilic esophagitis in children and adults: a systematic review and consensus recommendations for diagnosis and treatment. Gastroenterology. 2007 10;133(4):1342-63. [PubMed: 17919504]

14. Liacouras CA, Furuta GT, Hirano I, Atkins D, Attwood SE, Bonis PA, et al. Eosinophilic esophagitis: updated consensus recommendations for children and adults. J Allergy Clin Immunol. 2011 7;128(1):3-20.e6; quiz 21. [PubMed: 21477849]

15. Molina-Infante J, Bredenoord AJ, Cheng E, Dellon ES, Furuta GT, Gupta SK, et al. Proton pump inhibitor-responsive oesophageal eosinophilia: an entity challenging current diagnostic criteria for eosinophilic oesophagitis. Gut. 2016 3;65(3):524-31. [PubMed: 26685124]

16. Dellon ES, Liacouras CA, Molina-Infante J, Furuta GT, Spergel JM, Zevit N, et al. Updated international consensus diagnostic criteria for eosinophilic esophagitis: proceedings of the AGREE conference. Gastroenterology. 20189 6;155(4):1022-1033.e10. [PubMed: 30009819]

17. DeBrosse CW, Case JW, Putnam PE, Collins MH, Rothenberg ME. Quantity and distribution of eosinophils in the gastrointestinal tract of children. Pediatr Dev Pathol. 2006 6;9(3):210-8. [PubMed: 16944979]

18. Lwin T, Melton SD, Genta RM. Eosinophilic gastritis: histopathological characterization and quantification of the normal gastric eosinophil content. Mod Pathol. 2011 4;24(4):556-63. [PubMed: 21169993]

19. Khoury P, Akuthota P, Ackerman SJ, Arron JR, Bochner BS, Collins MH, et al. Revisiting the NIH Taskforce on the Research needs of Eosinophil-Associated Diseases (RE-TREAD). J Leukoc Biol. 20184 19;104(1):69-83. [PubMed: 29672914] 
20. O’Connell EM, Nutman TB. Eosinophilia in infectious diseases. Immunol Allergy Clin North Am. 2015 8;35(3):493-522. [PubMed: 26209897]

21. Chou A, Serpa JA. Eosinophilia in patients infected with human immunodeficiency virus. Curr HIV/AIDS Rep. 2015 9;12(3):313-6. [PubMed: 26126686]

22. Al Mohajer M, Villarreal-Williams E, Andrade RA, Giordano TP, Serpa JA. Eosinophilia and associated factors in a large cohort of patients infected with human immunodeficiency virus. South Med J. 2014 9;107(9):554-8. [PubMed: 25188618]

23. Flores M, Merino-Angulo J, Tanago JG, Aquirre C. Late generalized tuberculosis and eosinophilia. Arch Intern Med. 1983 1;143(1):182. [PubMed: 6849600]

24. Vijayan VK, Reetha AM, Jawahar MS, Sankaran K, Prabhakar R. Pulmonary eosinophilia in pulmonary tuberculosis. Chest. 1992 6;101(6):1708-9. [PubMed: 1600796]

25. Driss V, Legrand F, Hermann E, Loiseau S, Guerardel Y, Kremer L, et al. TLR2-dependent eosinophil interactions with mycobacteria: role of alpha-defensins. Blood. 20094 2;113(14):323544. [PubMed: 18978205]

26. Pfeffer PE, Hopkins S, Cropley I, Lowe DM, Lipman M. An association between pulmonary Mycobacterium avium-intracellulare complex infections and biomarkers of Th2-type inflammation. Respir Res. 20175 15;18(1):93. [PubMed: 28506264]

27. Herrick JA, Legrand F, Gounoue R, Nchinda G, Montavon C, Bopda J, et al. Posttreatment Reactions After Single-Dose Diethylcarbamazine or Ivermectin in Subjects With Loa loa Infection. Clin Infect Dis. 20174 15;64(8):1017-25. [PubMed: 28329346]

28. Rajamanickam A, Munisankar S, Bhootra Y, Dolla CK, Nutman TB, Babu S. Elevated Systemic Levels of Eosinophil, Neutrophil, and Mast Cell Granular Proteins in Strongyloides Stercoralis Infection that Diminish following Treatment. Front Immunol. 20182 9;9:207. [PubMed: 29479356]

29. Nutman TB, Miller KD, Mulligan M, Ottesen EA. Loa loa infection in temporary residents of endemic regions: recognition of a hyperresponsive syndrome with characteristic clinical manifestations. J Infect Dis. 1986 7;154(1):10-8. [PubMed: 3458832]

30. Thaden J, Cassar A, Vaa B, Phillips S, Burkhart H, Aubry M, et al. Eosinophilic endocarditis and Strongyloides stercoralis. Am J Cardiol. 20138 1;112(3):461-2. [PubMed: 23672985]

31. Romagosa R, Kapoor S, Sanders J, Berman B. Inpatient Adverse Cutaneous Drug Eruptions and Eosinophilia. | Allergy and Clinical Immunology | JAMA Dermatology | JAMA Network. Arch Dermatol. 20014 1;

32. Kuruvilla M, Khan DA. Eosinophilic Drug Allergy. Clin Rev Allergy Immunol. 2016 4;50(2):22839. [PubMed: 26006718]

33. Ramírez E, Medrano-Casique N, Tong HY, Bellón T, Cabañas R, Fiandor A, et al. Eosinophilic drug reactions detected by a prospective pharmacovigilance programme in a tertiary hospital. Br $\mathrm{J}$ Clin Pharmacol. 2017;83(2):400-15. [PubMed: 27543764]

34. Ogawa K, Morito H, Hasegawa A, Miyagawa F, Kobayashi N, Watanabe H, et al. Elevated serum thymus and activation-regulated chemokine (TARC/CCL17) relates to reactivation of human herpesvirus 6 in drug reaction with eosinophilia and systemic symptoms (DRESS)/drug-induced hypersensitivity syndrome (DIHS). Br J Dermatol. 20148 2;171(2):425-7. [PubMed: 24601914]

35. Tashiro Y, Azukizawa H, Asada H, Niihara H, Morita E, Yamauchi T, et al. Drug-induced hypersensitivity syndrome/drug reaction with eosinophilia and systemic symptoms due to lamotrigine differs from that due to other drugs. J Dermatol. 2019 3;46(3):226-33. [PubMed: 30663091]

36. Kardaun SH, Sidoroff A, Valeyrie-Allanore L, Halevy S, Davidovici BB, Mockenhaupt M, et al. Variability in the clinical pattern of cutaneous side-effects of drugs with systemic symptoms: does a DRESS syndrome really exist? Br J Dermatol. 2007 3;156(3):609-11. [PubMed: 17300272]

37. Kardaun SH, Sekula P, Valeyrie-Allanore L, Liss Y, Chu CY, Creamer D, et al. Drug reaction with eosinophilia and systemic symptoms (DRESS): an original multisystem adverse drug reaction. Results from the prospective RegiSCAR study. Br J Dermatol. 2013 11;169(5):1071-80. [PubMed: 23855313]

38. Chen Y-C, Chiu H-C, Chu C-Y. Drug reaction with eosinophilia and systemic symptoms: a retrospective study of 60 cases. Arch Dermatol. 2010 12;146(12):1373-9. [PubMed: 20713773] 
39. Cacoub P, Musette P, Descamps V, Meyer O, Speirs C, Finzi L, et al. The DRESS syndrome: a literature review. Am J Med. 2011 7;124(7):588-97. [PubMed: 21592453]

40. Eosinophilia-Myalgia Syndrome-New Mexico. JAMA. 198912 8;262(22):3116. [PubMed: 2810660]

41. Böhm A, Födinger M, Wimazal F, Haas OA, Mayerhofer M, Sperr WR, et al. Eosinophilia in systemic mastocytosis: clinical and molecular correlates and prognostic significance. J Allergy Clin Immunol. 2007 7;120(1):192-9. [PubMed: 17451799]

42. Maric I, Robyn J, Metcalfe DD, Fay MP, Carter M, Wilson T, et al. KIT D816V-associated systemic mastocytosis with eosinophilia and FIP1L1/PDGFRA-associated chronic eosinophilic leukemia are distinct entities. J Allergy Clin Immunol. 2007 9;120(3):680-7. [PubMed: 17628645]

43. Kalaycioglu ME, Bolwell BJ. Eosinophilia after allogeneic bone marrow transplantation using the busulfan and cyclophosphamide preparative regimen. Bone Marrow Transplant. 1994 7;14(1):1135. [PubMed: 7951097]

44. Bush JW, Mohammad S, Melin-Aldana H, Kagalwalla AF, Arva NC. Eosinophilic density in graft biopsies positive for rejection and blood eosinophil count can predict development of posttransplant digestive tract eosinophilia. Pediatr Transplant. 2016 6;20(4):540-51. [PubMed: 26917244]

45. Wechsler ME, Akuthota P, Jayne D, Khoury P, Klion A, Langford CA, et al. Mepolizumab or Placebo for Eosinophilic Granulomatosis with Polyangiitis. N Engl J Med. 20175 18;376(20):1921-32. [PubMed: 28514601]

46. Williams KW, Milner JD, Freeman AF. Eosinophilia Associated with Disorders of Immune Deficiency or Immune Dysregulation. Immunol Allergy Clin North Am. 2015 8;35(3):523-44. [PubMed: 26209898]

47. Milner JD, Ward JM, Keane-Myers A, Paul WE. Lymphopenic mice reconstituted with limited repertoire T cells develop severe, multiorgan, Th2-associated inflammatory disease. Proc Natl Acad Sci USA. 2007 19;104(2):576-81. [PubMed: 17202252]

48. Lucendo AJ, Arias Á, González-Cervera J, Yagüe-Compadre JL, Guagnozzi D, Angueira T, et al. Empiric 6-food elimination diet induced and maintained prolonged remission in patients with adult eosinophilic esophagitis: a prospective study on the food cause of the disease. J Allergy Clin Immunol. 2013 3;131(3):797-804. [PubMed: 23375693]

49. Molina-Infante J, Arias Á, Alcedo J, Garcia-Romero R, Casabona-Frances S, Prieto-Garcia A, et al. Step-up empiric elimination diet for pediatric and adult eosinophilic esophagitis: The 2-4-6 study. J Allergy Clin Immunol. 2018 4;141(4):1365-72. [PubMed: 29074457]

50. Kagalwalla AF, Sentongo TA, Ritz S, Hess T, Nelson SP, Emerick KM, et al. Effect of six-food elimination diet on clinical and histologic outcomes in eosinophilic esophagitis. Clin Gastroenterol Hepatol. 2006 9;4(9):1097-102. [PubMed: 16860614]

51. Castro M, Corren J, Pavord ID, Maspero J, Wenzel S, Rabe KF, et al. Dupilumab Efficacy and Safety in Moderate-to-Severe Uncontrolled Asthma. N Engl J Med. 20186 28;378(26):2486-96. [PubMed: 29782217]

52. Valent P, Klion AD, Horny H-P, Roufosse F, Gotlib J, Weller PF, et al. Contemporary consensus proposal on criteria and classification of eosinophilic disorders and related syndromes. J Allergy Clin Immunol. 20129 1;130(3):607-612.e9. [PubMed: 22460074]

53. Klion AD. How I treat hypereosinophilic syndromes. Blood. 20158 27;126(9):1069-77. [PubMed: 25964669]

54. Prakash Babu S, Chen YYK, Bonne-Annee S, Yang J, Maric I, Myers TG, et al. Dysregulation of interleukin 5 expression in familial eosinophilia. Allergy. 2017 9;72(9):1338-45. [PubMed: 28226398]

55. Klion AD, Law MA, Riemenschneider W, McMaster ML, Brown MR, Horne M, et al. Familial eosinophilia: a benign disorder? Blood. 20046 1;103(11):4050-5. [PubMed: 14988154]

56. Kuang FL, Fay MP, Ware J, Wetzler L, Holland-Thomas N, Brown T, et al. Long-Term Clinical Outcomes of High-Dose Mepolizumab Treatment for Hypereosinophilic Syndrome. J Allergy Clin Immunol Pract. 20185 8;6(5):1518-1527.e5. [PubMed: 29751154] 
57. Ogbogu PU, Bochner BS, Butterfield JH, Gleich GJ, Huss-Marp J, Kahn JE, et al. Hypereosinophilic syndrome: a multicenter, retrospective analysis of clinical characteristics and response to therapy. J Allergy Clin Immunol. 2009 12;124(6):1319-25.e3. [PubMed: 19910029]

58. Pongdee T, Khoury P, Klion AD. Myeloproliferative hypereosinophilic syndrome: retrospective analysis of cytogenetic and molecular features. Journal of Allergy and Clinical Immunology. 2018 2;141(2):AB277.

59. Kuang FL, Legrand F, Makiya M, Ware J, Wetzler L, Brown T, et al. Benralizumab for PDGFRANegative Hypereosinophilic Syndrome. N Engl J Med. 20194 4;380(14):1336-46. [PubMed: 30943337]

60. Legrand F, Klion AD. Biologic therapies targeting eosinophils: current status and future prospects. J Allergy Clin Immunol Pract. 2015 4;3(2):167-74. [PubMed: 25754717]

61. Panch SR, Bozik ME, Brown T, Makiya M, Prussin C, Archibald DG, et al. Dexpramipexole as an oral steroid-sparing agent in hypereosinophilic syndromes. Blood. 20188 2;132(5):501-9. [PubMed: 29739754]

62. Laidlaw TM, Prussin C, Panettieri RA, Lee S, Ferguson BJ, Adappa ND, et al. Dexpramipexole depletes blood and tissue eosinophils in nasal polyps with no change in polyp size. Laryngoscope. 2019 2;129(2):E61-6. [PubMed: 30284267]

63. Roufosse FE, Kahn J-E, Gleich GJ, Schwartz LB, Singh AD, Rosenwasser LJ, et al. Long-term safety of mepolizumab for the treatment of hypereosinophilic syndromes. J Allergy Clin Immunol. 2013 2;131(2):461-7.e1. [PubMed: 23040887]

64. Lee JJ, Jacobsen EA, McGarry MP, Schleimer RP, Lee NA. Eosinophils in health and disease: the LIAR hypothesis. Clin Exp Allergy. 2010 4;40(4):563-75. [PubMed: 20447076] 


\section{KEY POINTS}

- $\quad$ Peripheral blood eosinophilia is defined using absolute eosinophil count (AEC in cells $/ \mathrm{mm}^{3}$ ). Eosinophil percentages can be misleading.

- A careful history and physical exam are important in addressing the cause of the eosinophilia.

- Degree of eosinophilia is not always correlated with severity or seriousness of disease.

- Medications are the most common cause of eosinophilia in the developed world while parasitic infections are the most common cause worldwide.

- Concomitant medications (such as corticosteroids) and transient medical conditions (bacterial infection) can mask a greater degree of eosinophilia by temporarily suppressing the AEC.

- $\quad$ Sustained hypereosinophilia (AEC $\geq 1500$ cells $/ \mathrm{mm} 3$ ) without clear cause should prompt an evaluation for hypereosinophilic syndrome, especially if the patient is symptomatic. 


\section{SYNOPSIS}

Physicians may encounter blood or tissue eosinophilia through a routine $\mathrm{CBC}$ with differential or a tissue pathology report. In this article, the basic biology of eosinophils will be reviewed and definitions of blood eosinophilia as well as the challenges of defining tissue eosinophilia will be discussed. Conditions associated with eosinophilia will be briefly discussed as well as a general approach to evaluating eosinophilia. Future challenges include determining which eosinophil-associated diseases benefit from eosinophil-targeted therapy and identifying biomarkers for disease activity and diagnosis. 
Table 1 -

\section{RegiSCAR Scoring System for DRESS}

\begin{tabular}{|c|c|c|}
\hline & Details & Scoring \\
\hline Fever $>=38.5^{\circ} \mathrm{C}-$ & Absent | Present & $-1 \mid 0$ \\
\hline \multicolumn{3}{|l|}{ Enlarged Lymph Nodes - } \\
\hline Eosinophilia & Absent | AEC 700-1499/uL | AEC $\geq 1500 / \mu 1$ & $0|1| 2$ \\
\hline Atypical Lymphocytes & Absent | Present & $0 \mid 1$ \\
\hline \multicolumn{3}{|l|}{ Skin Findings } \\
\hline Skin Rash Extent & Absent $\mid \geq 50 \%$ & $0 \mid 1$ \\
\hline Skin rash suggesting DRESS & Absent | Uncertain | Present & $-1|0| 1$ \\
\hline Biopsy suggesting DRESS & Absent $\mid$ Present or uncertain & $-1 \mid 0$ \\
\hline $\begin{array}{l}\text { Organ Involvement }^{*} \\
\text { Liver, Kidney, Lung, Muscle, Heart, pancreas and others }\end{array}$ & Absent $\mid$ Present $\mid>1$ organ & $0|1| 2$ \\
\hline Resolution $>15$ days & Absent | Present & $-1 \mid 0$ \\
\hline $\begin{array}{l}\text { Evaluation for Other Causes } \\
\text { ANA } \\
\text { Blood Culture } \\
\text { Serology HVA/HVB/HVC } \\
\text { Chlamydia/M. pneumonia } \\
\text { Other serology/PCR }\end{array}$ & $>3$ other causes evaluated and negative & 1 \\
\hline
\end{tabular}

After exclusion of other explanations. Points are tallied. Final score $<2$ : No Case

Final Score 2-3: Possible Case; Final score 4-5: Probable Case; Final score >5: Definite Case

Adapted from Kardaun SH, Sekula P, Valeyrie-Allanore L, et al. Drug reaction with eosinophilia and systemic symptoms (DRESS): an original multisystem adverse drug reaction. Results from the prospective RegiSCAR study. Br J Dermatol 2013;169(5):1074; with permission. 